\title{
NEOLIBERALISMO E CADEIAS GLOBAIS: UMA ANÁLISE DE GOVERNAMENTALIDADE E MENSAGEM
}

Aparecido Silva ${ }^{1}$

\begin{abstract}
RESUMO: O presente trabalho é uma tentativa de averiguar as formas de dominação e a relação de poder atuantes em economias populares e informal, em contexto neoliberal e na base de Cadeias Globais, mais especificamente no interior das firmas. Para tal propósito trabalhamos com dois conceitos, de governamentalidade e de mensagem. Conceitos estes desenvolvidos por dois autores, Verónica Gago e Lee Pegler. Para pensar tais conceitos é importante destacar o espaço e o território, como lugar de tensionamentos, de trocas e de disciplinamento desses trabalhadores, que podem ser consciente ou não. Num primeiro momento, será realizado um pequeno esboço das políticas neoliberais e das cadeias globais, posteriormente apresentamos os conceitos de governança e mensagem, observando como esses dispositivos de dominação opera na construção da vida dos trabalhadores.
\end{abstract}

Palavras-chave: Lógica, Mensagem, Governamentalidade.

\section{NEOLIBERALISM AND GLOBAL CHAINS: AN ANALYSIS OF GOVERNMENTALITY AND MESSAGE}

\begin{abstract}
The present work is an attempt at media as forms of domination and a power relationship active in popular and informal policies, in a neoliberal context and $n$ the basis of Global Chains, more specifically within firms. For this purpose, work with two concepts, governance and message. Concepts developed bay two authors, Verónica Gago and Lee Pegler. To think about these concepts, it is importante to highlifht the space and territory, as a place of tension, exchangers and disciplining of the workers, which may be conscious or not. At first, a small outline of neoliberal policies and global chains will be carried out, later on the concepts of governance and messages, observing how these devices of domination in the construction of workers lives.
\end{abstract}

Keywords: Logic, Message, Governmentality.

\section{INTRODUÇÃO}

O presente trabalho busca compreender as novas dinâmicas de controle no processo de produção e trabalho em contexto do neoliberalismo e nas Cadeias Globais. Assim, os argumentos fundamentais deste texto girarão em torno de dois autores,

\footnotetext{
${ }^{1}$ Doutorando pelo programa de Pós-Graduação em Sociologia da Universidade Federal Fluminense UFF. Membro do grupo de pesquisa FRONTEIRAS, liderado pelo professor Valter Lúcio de Oliveira. Email: aparecidosilva25@hotmail.com.
} 
Verónica Gago (2014) e Lee Pegler (2011). Em primeiro momento, fará uma pequena exposição da política neoliberal no contexto da América Latina e das Cadeias Globais, para posteriormente, pensar como o neoliberalismo e as cadeias globais atuam direta e indiretamente via Estado e nas relações de poder, sejam eles em governos conservadores ou em governos considerados progressistas. Um dos pontos principais desse trabalho é pensar que mesmo em crise o neoliberalismo opera de forma lógica, racional e moral na produção da vida, ou seja, entende-se que o neoliberalismo não fracassou e sim, remodelou, ele se refez em outras formas de operar.

A chave foucaultiana é justamente esta: a força do neoliberalismo como governamentalidade é incluir a "liberdade", essa ideia que modernamente colocava em perigo toda ordem, inclusive dentro do próprio núcleo de um novo dispositivo de ordem livre (GAGO, 2014, p.238).

Gago (2014) chamou esse novo modelo de política econômica de "Neoliberalismo a partir de baixo". Essa conceituação será desenvolvida ao longo do texto, buscando estabelecer uma relação de proximidade com o texto de Lee Pegler (2011).

Já na introdução de seu texto, Lee Pegler, traz para a discussão o processo de cultivo de frutas na Amazônia, destacando a divisão do trabalho - familiar que acaba fornecendo sua produção para uma cadeia de compradores e organizadores no norte global. Ele vai trabalhar com conceitos de Cadeia Global, mostrando como suas estruturas de governança desempenham, define e modela a posição de ganhadores e perdedores. Nesse sentido, são os trabalhadores e fornecedores o ponto inicial dessa cadeia global, principalmente nos países em desenvolvimento.

Ambos os autores, Gago (2014) e Pegler (2011) buscaram compreender essa nova dinâmica da produção via trabalhos de campo, mais precisamente com estudos de caso. Os autores trabalham com pontos comuns, de governamentalidade e mensagem, conceitos este atribuídos ao filósofo Michel Foucault. Pensar a política neoliberal e as Cadeias Globais a partir de "baixo" possibilitará uma maior compreensão de seus impactos diretos e indiretos nos trabalhadores de base e nas suas condições de trabalho. 


\section{CONTEXTO NEOLIBERAL NA AMÉRICA LATINA E AS CADEIAS GLOBAIS}

As políticas neoliberais foram adotadas na América Latina a partir da década de 70 do século XX como um rearranjo do capital. Imerso nas políticas neoliberais temos as Cadeias Globais operando através das firmas, principalmente das transnacionais. São Cadeias Globais, "É a internacionalização das atividades desenvolvidas por firmas (especialmente processos de manufatura) está disseminada por diferentes indústrias em diferentes regiões do mundo, em escala sem precedentes” (2014 Zhang, Silvana, 2014). As características das políticas neoliberais são: privatização de empresas públicas, flexibilização das leis trabalhistas, e a construção de um imaginário de que o Estado será ausente, mas na verdade ele é o fomentador de tais políticas. Gago (2014) afirma que esse modelo neoliberal que opera de cima para baixo não prosperou, o neoliberalismo que está se mantendo é o neoliberalismo, "de baixo para cima". "E, de baixo para cima, o neoliberalismo é a proliferação de modos de vida que reorganizam as noções de liberdades, cálculos e obediências, projetando uma nova racionalidade e afetividade coletiva" (Gago, 2014, p.17). Tais elementos foram detectados pelos autores em novas configurações, dentre elas o consumo, a subjetividade e principalmente no reconhecimento de que essa forma de organização do trabalho é agência. Neste sentido, é no trabalho informal que se configura um novo modelo de neoliberalismo, o qual é guiado e organizado de formas coletivas, de forma comunitária e também na estrutura familiar.

Dentro desse escopo, pode-se inferir que, neoliberalismo tal qual se conhecia nas décadas de 80 do século XX, entrou em crise. Se por um lado, as políticas neoliberais verticalizadas, entraram em crise, as cadeias globais se desenvolveram nesses espaços, em consonância com o neoliberalismo remodelado. O neoliberalismo (de baixo para cima) é entendido também como resistência. Segundo Gago,

Essa hipótese está na base de uma ampliação- temática e conceitual- da própria noção de neoliberalismo e, portanto, da projeção de uma nova efetividade e racionalidade para traçar o mapa político dessas economias fortemente expansivas das abigarradas cidade latino-americanas (GAGO, 2014, p.21). 
Assim, o neoliberalismo vai se reconfigurando e a macropolítica vinda das grandes potências vão perdendo espaço.

Da América Latina, é preciso completar Foucault a partir das revoltas da última década, ancorado aqui a crítica ao neoliberalismo como um modo de poder, dominação e espoliação, ao mesmo tempo que se discute as imagens e as formas de felicidade políticas que estão em jogo nas diversas noções de liberdades que simultaneamente competem no neoliberalismo(GAGO, 2014, p.24).

Essa nova forma de operar neoliberal carrega consigo traços de produtividade, que até então, não eram percebidos, “[...] Ou seja, é um modo de cooperação social que reorganiza o horizonte do trabalho e da exploração, da integração e do progresso, da boa vida e do bom governo" (GAGO, 2014, p. 25).

Ao se pensar no neoliberalismo no âmbito do capitalismo clássico, o que vem ao imaginário é a adoção de políticas direcionadas das grandes potências econômicas via suas agências, voltadas a minimização do Estado, privatizações das estatais, flexibilização das leis trabalhistas etc. O modelo neoliberal clássico tem como foco as instituições particulares, lideradas pelas empresas multinacionais e transnacionais, as quais obrigam os países periféricos a adotá-las de diversas maneiras.

Os dois autores mobilizados para pensar esse trabalho trazem uma perspectiva inovadora dentro da ciência social para entender esse fenômeno vias outros aspectos, qual seja, da base. De certa maneira, esse modelo neoliberal clássico passou a operar de forma desestruturada se pensando no modelo clássico, pois uma das características desse neoliberalismo de baixo para cima é a informalidade. Segundo Gago,

\footnotetext{
Nosso uso específico refere-se à composição estratégia de elementos microempresárias, com fórmulas de progresso popular, com capacidades de negociação e disputa de recursos estatais e eficazes na sobreposição de vínculos de parentesco e de lealdade ligados ao território, assim como formatos contratuais não tradicionais (GAGO, 2014, p.29).
}

Nesse sentido, são mobilizados dois conceitos de informalidades, O informal como fonte instituinte e aincomensurabilidade. Esses dois conceitos são importantes para compreender esse neoliberalismo não pensado, pelo menos a princípio pelas agências internacionais, tais como Banco Mundial, Fundo Monetário Internacional e as 
transnacionais. De forma geral, esse informal seria "O informal nesse sentido não se refere àquilo que não tem forma, mas a dinâmica que inventa e promove formas produtivas, comerciais, relacionais etc" (Gago, 2014, p.30). A autora vai trabalhar com conceitos foucaultianos, mas buscando complexificá-los na medida em que traz para o debate as novas formas de produção e o modo que sustenta essa produção de economia popular na Argentina, buscando desmitificar a ideia de que os setores populares vistos como vítimas, aqui eles são vistos como protagonistas, seja de maneira racional ou não.

\section{GOVERNAMENTALIDADE E MENSAGEM}

Diversas foram às teorias voltadas para entender as formas de dominação, seja elas sociais, políticas, culturais e econômicas. Aqui trabalharemos com os conceitos de governamentalidade e mensagem. Para Pegler, Governamentalidade pode ser entendida como sendo a legitimação do poder e do controle a distância. Ele vai buscar na perspectiva de Foucault elementos para pensar como esses trabalhadores agem, assim, entende que o poder opera via processo disperso, influenciando o sujeito e até modelando em função de suas circunstâncias históricas. Assim, o conceito de governamentalidade pode ser compreendido como sendo a maneira como o poder atua sobre os outros e sobre si. Importante destacar que em ambos os trabalhos a ideia de governança se faz presente via processo técnico científico, manifestando na organização interior dos trabalhadores seja no espaço informal ou na base da cadeia via mensagem.

Esses conceitos foram percebidos no trabalho de campo desenvolvidos por Verônica Gago, na feira de La Salada e nos estudos de Cadeias Globais de Lee Pegler. La Salada é um espaço de produção em que diversos indivíduos, estrangeiros, paraguaios, bolivianos, peruanos e chilenos encontram-se no processo de produção. "La Salada, em seu caráter aparentemente marginal, é um ponto de uma rede transnacional em expansão, e um lugar privilegiado para se mostrar a multiplicidade de economias e de processos de trabalho heterogêneos, materializados no sistema econômico global” (Gago, 2014, p.38). Segundo Monteiro,

[...] as Oficinas integram uma trama que propõe pensar a cidade como heterogênea, desprovida de uma ordem única, onde se pensa o trabalho, o consumo e o comunitário através do desenvolvimento de uma sociedade 
neoliberal a partir não só dos governos, mas também dos governados. Gago consegue apresentar uma análise com nós desatados a partir de uma rigorosa e eficaz metodologia, sem deixar a qualidade textual cair ou permitir que a leitura fique enfadonha (MONTEIRO, 2020, p.193).

A partir dos dois autores podemos inferir que globalização e neoliberalismo são modelos políticos e econômicos que não operam apenas de cima para baixo, ou seja, verticalizados, agora são as comunidades, os indivíduos, a família, os sindicatos e as organizações coletivas e individualmente, que estabelecem laços e também tensinamnetos.

Assim, a governametalidade e a mensagem são dois conceitos que vão operar em uma suposta autovalorização do indivíduo, da comunidade, da família e da liberdade, estabelecendo correntes, elos e teias racionalizadas que parte do local ao global. Trabalhadores e trabalhadoras reunidos, a princípio por objetivos aparentemente individuais, mas ao se analisar essas relações percebe-se que esses trabalhadores fazem parte de uma rede complexas que está para além do local. Dentro desse escopo, o conceito de governamentalidade elucida tais relações,

\footnotetext{
Pode nos oferecer uma ponte conceitual mais firme entre aspectos estruturais da organização das cadeias e o estabelecimento e a legitimação dos valores que são observadores no interior e ao longo das cadeias. $\mathrm{O}$ conceito também pode, portanto, oferecer pistas mais robustas sobre como a contestação e a dinâmica de poder levam a resultados particulares sobre a organização do trabalho e da subsistência, assim como sobre a forma como poderíamos estudá-las (PEGLER, 2011, p. 23).
}

Pegler questiona a premissa de que a entrada das firmas na cadeia global traz melhorias, e ampliação de cidadania a classe trabalhadora de ponta da produção e sim traz a vulnerabilidade e flexibilidade de direitos já adquiridos, o que acaba afetando a cooperação e a solidariedade no interior das firmas, ou seja, o trabalho decente.

Nas relações no interior de La Salada, Gago observa os processos socioeconômicos e reflete, questiona a ideia de que as políticas neoliberais operam apenas verticalmente. Seguindo a ideia de mensagem e governamentalidade as relações econômicas são percebidas na base das relações entre os trabalhadores informais (trabalhadores que não estão em regime de trabalho formal, carteira assinada regido pelas leis trabalhistas). Essa "desorganização, organizada" foi construída na crise do 
neoliberalismo o que não se pode afirmar que o neoliberalismo deixou de existir, ele se remodelou de forma mais precária, porém eficiente. Para entender esse novo fenômeno é importante voltar-se para a comunidade. "Desse modo, a questão da comunidade é um conceito-chave para analisar problemas transversais à economia, pois expressa um nível em que o próprio coletivo se define antes por um conjunto de práticas comuns - de linguagens, de costumes, de vínculos, de valores etc”, (GAGO, 2014, p.112). A linguagem funciona como elemento composto pelos estrangeiros, pelos pobres, pelas mulheres é um conectivo para manter a econômica informal movimentando. $\mathrm{O}$ avanço dessa economia pode ser atribuída ao desemprego estrutural e o apoio do Estado, das ONGs mesmo de forma tímida via subsídios para esses segmentos sociais.

\footnotetext{
O saber-fazer do trabalho doméstico-reprodutivo, junto com um complexo repertório de práticas e conhecimentos comunitários, montou uma trama de economias múltiplas em meio à crise que permitiu a sobrevivência de milhares de pessoas, ao mesmo tempo que projetou uma capacidade política de autogestão popular de grande alcance (GAGO, 2014, p.119).
}

Essa comunidade de trabalhadoras e trabalhadores que se camuflam nas oficinas que é composta por estrangeiros, peruanos, bolivianos, paraguaios e chilenos, engloba também a questão de gênero. Nesse sentido, alguns códigos são acionados para que essa movimentação econômica permaneça, o feminismo e os migrantes, os aspectos étnicos e culturais. Juntando a isso o desemprego estrutural e a resistência ajudaram a alavancar essa economia de baixo para cima. Então, os conceitos de mensagens e governamentalidade são essenciais para manutenção desse modo de ser, seja, ele individual ou coletivo, mas sem descartar, como bem destacou Foucault, as instituições. Segundo Foucault,

\footnotetext{
Por 'governamentalidade' entendo o conjunto constituído pelas instituições, procedimentos, análises e reflexões, os cálculos e as táticas que permitem exercer essa forma bem específica, ainda que complexa, de poder que tem por alvo principal a população, por forma maior de saber a economia política, por instrumento técnico essencial os dispositivos de segurança. (FOUCAULT, 2004, p.111).
}

Assim, os dispositivos acionados de maneira racionalizada no interior de Lá Salada, como na base da Cadeia Global, operam via meios tecnológicos e de linguagem 
de discurso no processo de dominação. Dominação esta que aprece muitas vezes de forma subjetivas, não aparentando que existem relações de poder operando no território. Segundo, Pegler,

\begin{abstract}
De uma perspectiva da seguridade humana, estas "motivações internas" se relacionam a aspectos tais como: o grau em que os trabalhadores/pessoas distinguem a qualidade de vida do simples consumo; o grau em que eles são movidos por solidariedade $\mathrm{x}$ individualismo; e o grau em que suas atividades se baseiam em uma crença pessoal na necessidade da regeneração da natureza, ao invés do domínio e exploração (PEGLER, 2011, p.15).
\end{abstract}

Neste sentido, as relações de poder se fazem presente de forma sutil, e em muitos casos os trabalhadores acabam naturalizando tal processo via cultura, assim, pode-se inferir que as Cadeias Globais como no neoliberalismo se representam em processo físico de produção que ligam países, grupos sociais, étnicos e locais via em processos que incorporam mensagens, lógicas que são transmitidas através do espaço e tecnologias. Outro dispositivo acionado é a liberdade individual, a liberdade coletiva e a individualização do sujeito.

A arte de governar se transforma radicalmente: trata-se agora de respeitar a proliferação de iniciativas, de não as limitar, enfim: governar é "saber como dizer sim a esse desejo". Desejo como sinônimo de iniciativa livre, como impulso de desenvolvimento do próprio capitalismo (GAGO, 2014, p.229).

Esse modo de governar valorizando e enfatizando a liberdade individual, pode ser entendido como naturalização dos acontecimentos. Nesse sentido, a liberdade é utilizada pela política neoliberal como base de suas ações, ou seja, a liberdade passa a ser calculada, computada, ela se torna um produto para o mercado. Assim, a vida passa também a ser uma mercadoria e a ser dominada.

Para Gago, nesse tipo de dominação, "É também descentralização do estatal em nome de uma dinâmica diretamente empresarial o que termina por diluir toda meditação do indivíduo consigo mesmo, com a gestão de si [...]" (Gago, 2014, p.233).

Como imbricação paralela entre uma noção cada vez mais complexa de indivíduo (como singularidade, autonomia e investigação permanente sobre si) e um modo padronizado de funcionamento coletivo que opera na população, exigindo e reduzindo ao mesmo tempo a contínua singularização de cada um (GAGO, 2014, p.234). 
A governamentalidade e a mensagem são instrumentos que operam no chamado de neoliberalismo de baixo para cima, principalmente na crise do neoliberalismo na década de 2000 na Argentina, o que levou ao aumento drasticamente o desemprego e da pobreza. No caso da Argentina, a autora diz que foi uma crise de legitimação da política e não a ausência do estado. Segundo a autora,

\begin{abstract}
O intuito de propor falar de um neoliberalismo de baixo para cima é reconhecer a complexidade do neoliberalismo, que não pode ser definido de maneira homogênea, assim como depende de suas ligações e montagens com situações concretas. Estas obrigam o neoliberalismo a se pluralizar para além de sua definição como um conjunto de políticas emanadas de cima, como planificação estrutural (GAGO, 2014, p.237).
\end{abstract}

Dentro desse escopo, pode-se inferir que o neoliberalismo é uma política que opera segundo a via vertical- com direcionamentos disparados do topo das empresas e também de baixo- principalmente a partir do trabalho informal.

\title{
CONSIDERAÇÕES FINAIS
}

Os autores trabalhados nesse pequeno texto trazem para a discussão novas possibilidades de entender a política neoliberal de baixo para cima, pensando numa aproximação com o marxismo, poderíamos dizer que Gago e Pegler buscam essa compreensão via território, a economia popular e os trabalhadores como elementos centrais para tais acontecimentos, "Elas são o espaço-tempo de economias situadas que se tornam essenciais para pensar o modo em que o capital, através da diversificação das formas financeiras, tenta incorporar novos territórios" (GAGO, 2014, p.260). Esses trabalhadores, de uma forma ou de outra, buscam sua inserção no mercado capitalista seja na sua produção e melhorias nas condições de trabalho, como também na reivindicação de políticas públicas.

Isso ficou claro na produção e na atuação desses trabalhadores, bolivianos, peruanos, paraguaios, e chilenos possibilitando uma organização política popular via participação. Segundo Gago, 


\begin{abstract}
Desse modo, a villa, como âmbito de um internacionalismo forçoso, tornouse possibilidade de inovação política popular, desafio às formas organizacionais existentes e criou, durante vários anos (1999-2004), meios de participação, disputa e negociação, misturando estratégias, discursos, tradições e trajetórias de origens diversas (GAGO, 2014, p. 274).
\end{abstract}

Assim, os conceitos de governamenatalidades e mensagem operam nesses espaços, "Estudos sobre governamentalidade procuram iluminar a maneira como o poder atua sobre outros e sobre $s i$ - como se desenvolve uma mensagem particular a respeito de "como as coisas são feitas [...] e como esta mensagem é ou não sustentada" (PEGLER, 2011, p.24). Esse processo segue uma lógica de dominação no interior das cadeias, maneira pela qual vai construindo uma racionalidade, uma subjetividade do indivíduo, que opera no interior da cadeia, construindo um processo mais amplo da produção. Uma produção que é local e ao mesmo tempo global. Dentro da crise do neoliberalismo e da globalização, a produção local acaba sendo o espaço, o território de sustentação desses processos. Assim, na governamentalidade a dominação se dá via lógica, muitas vezes não racional, sendo fixa ou não, pois a governamentalidade, assim, como a sociedade passa por mutações.

Seja na América Latina ou em países de economia subdesenvolvida, o processo de dominação se dá via governança e afins, usando a mensagem como dispositivo de controle para manutenção da relação de poder. Tal mensagem é constantemente medida e avaliada via políticas para testar sua funcionalidade. Dentro desse escopo, a mensagem perpassa todas as esferas da cadeia produtiva e das políticas neoliberais, sejam elas verticalizadas ou horizontalizadas, que são muitas vezes disparadas do topo da cadeia até chegar à base e se naturalizar.

\title{
REFERÊNCIAS BIBLIOGRÁFICAS
}

FOUCAULT, M. 2004a. Sécurité, territoire, population: Cours au Collège de France, 1977-1978. Paris, Gallimard/ Seuil, p. 435.

GAGO, Verónica. A razão neoliberal: economias barrocas e pragmáticas popular/Verónica Gago; tradução de Igor Peres, - São Paulo: elefante, 2018.

PEGLER, Lee. Cadeias de valor sustentáveis e trabalho: dos conceitos à prática. Tradução de Cristiano Fonseca. Rio de Janeiro: 20011. Disponível em: <www.periodicoseletronicos.ufma.br>. Acesso em: 04 de jul. de 2020. 
MONTEIRO, R. A., «Gago, Verónica (2018). A razão neoliberal: economias barrocas e pragmática popular», Revista Crítica de Ciências Sociais [Online]. Disponível em: <OpenEdition Journals.journals.openedition.org>. Acesso em: 11 de maio de 2020

SCHIMANSKI, Silvana; ZHANH, Liping. Cadeias globais de valor e os países em desenvolvimento. Disponível em: <http://repositorio.ipea.gov.br/handle/11058/5322>. Acesso 18 de maio de 2020. 